\title{
High-nitrogen 23Cr9Mn1N steel manufactured by aluminothermy under nitrogen pressure: structure and mechanical properties
}

\author{
I. V. Sapegina ${ }^{\dagger}$, G. A. Dorofeev, M. I. Mokrushina, B. E. Pushkarev, V. I. Lad’yanov \\ †sairvl@mail.ru
}

Physical-Technical Institute of Ural Branch of RAS, 132 Kirov st., 426000, Izhevsk, Russia

\begin{abstract}
High-nitrogen steels are promising materials possessing a combination of high properties of strength, ductility and corrosion resistance. However, a powerful and complex equipment is required for the production of high-nitrogen steels by metallurgy methods under high nitrogen pressure. From energy-saving viewpoint, one of alternative and more attractive techniques is aluminothermy or reduction of metal oxides by metallic aluminum. The high temperature synthesis process occurs in this case due to the chemical energy of exothermic oxidation-reduction reaction. In the present work, the microstructure and mechanical properties of high-nitrogen steel $23 \mathrm{Cr} 9 \mathrm{Mn} 1 \mathrm{~N}$ (wt.\%) produced by aluminothermic SHS-metallurgy under nitrogen pressure using thermodynamic modeling are investigated. The melt was saturated with nitrogen simultaneously from the gas phase and chromium nitrides in the charge. As-cast steel has ferrite-austenitic structure with indications of austenite discontinuous decomposition with $\mathrm{Cr}_{2} \mathrm{~N}$ precipitations. The average grain size of the steel is about $16 \mu \mathrm{m}$. Forging at $T=1150-1170^{\circ} \mathrm{C}$ of the cast steel leads to a refinement of the structure and increase of the austenite fraction in the steel. After heat treatment of the forged sample (quenching in water from $1200^{\circ} \mathrm{C}$ ), there is a single austenite phase. The analysis of change of austenite FCC lattice parameter in the process of structure evolution under hot plastic deformation and heat treatment is carried out. Investigation of mechanical properties shows a combination of high values of strength and plasticity of steel after quenching. A conclusion is drawn that by aluminothermy one can obtain high-nitrogen steel, which has mechanical properties not worse than those of steel obtained by electroslag remelting under a nitrogen pressure.
\end{abstract}

Keywords: high-nitrogen austenitic steel, structure, mechanical properties, aluminothermy under nitrogen pressure.

\section{Высокоазотистая сталь 23Cr9Mn1N, полученная алюминотермией под давлением азота: структура и механические свойства}

\author{
Сапегина И. В. ${ }^{\dagger}$ Дорофеев Г. А., Мокрушина М. И., Пушкарев Б. Е., Ладьянов В. И. \\ Физико-технический институт УрО РАН, ул. Кирова 132, 426000, Ижевск, Россия
}

Высокоазотистые стали являются перспективными материалами, обладающими сочетанием высоких свойств прочности, пластичности и коррозионной стойкости. Однако для производства высокоазотистой стали методами металлургии под высоким давлением азота требуется энергоемкое и сложное оборудование. С точки зрения энергосбережения альтернативным и более привлекательным является метод алюминотермии, восстановления оксидов металлов металлическим алюминием. Высокотемпературный процесс синтеза при этом протекает за счет химической энергии экзотермической окислительно-восстановительной реакции. В работе исследованы микроструктура и механические свойства высокоазотистой стали 23Cr9Mn $1 \mathrm{~N}$ (мас.\%), полученной алюминотермическим методом СВС-металлургии под давлением азота с использованием термодинамического моделирования. Насыщение расплава азотом происходило одновременно из газовой фазы и с помощью нитридов хрома в составе шихты. В литом состоянии стали формируется феррито-аустенитная структура с признаками прерывистого распада аустенита с выделением $\mathrm{Cr}_{2} \mathrm{~N}$. Средний размер зерна стали $\sim 16$ мкм. Ковка при $T=1150-1170^{\circ} \mathrm{C}$ литой стали приводит к измельчению структуры и увеличению доли аустенита в стали. После термообработки кованого образца (закалка в воду от $\left.1200^{\circ} \mathrm{C}\right)$ наблюдается единственная фаза - аустенит. Выполнен анализ изменения параметра ГЦК решетки аустенита в процессе эволюции структуры при горячей пластической деформации и термообработке. Исследование механических свойств показало сочетание высоких значений прочности и пластичности стали после закалки. Сделан вывод, что методом алюминотермии может быть получена высокоазотистая сталь по механическим свойствам не уступающая сталям, полученным электрошлаковым переплавом под давлением азота.

Ключевые слова: высокоазотистая аустенитная сталь, структура, механические свойства, алюминотермия под давлением азота. 


\section{1. Введение}

Высокоазотистые стали (ВАС) получили применение в различных отраслях промышленности поскольку выгодно сочетают в себе высокие свойства прочности, пластичности и коррозионной стойкости [1-3]. Азот, как легирующий элемент ВАС, превосходит другие элементы по аустенитообразующей и упрочняющей способности, поэтому использование азота в сталях позволяет решать проблемы экономии дорогих и дефицитных легирующих элементов, таких как никель, ванадий, кобальт и др. $[4,5]$. Однако существует две проблемы при выплавке ВАС: как получить высокое (до $1 \%$ - здесь и далее концентрации приведены в мас.\%) содержание азота в расплаве, когда растворимость азота при атмосферном давлении не превышает $0.3 \%$, и как удержать азот в растворе при кристаллизации. Поэтому плавку BAC требуется проводить под давлением азота с использованием достаточно сложного и энергоемкого металлургического оборудования (металлургия под давлением), что удорожает их производство [6].

Существует более простой в осуществлении и менее затратный способ получения металлов и сплавов восстановлением их оксидов металлическим алюминием алюминотермия [7]. При проведении алюминотермического синтеза в атмосфере азота происходит насыщение расплава этим элементом и предотвращается выход азота из слитка в процессе охлаждения.

В данной работе проведены исследования структуры и механических свойств безникелевой ВАС состава $23 \mathrm{Cr} 9 \mathrm{Mn} 1 \mathrm{~N}$, полученной алюминотермическим методом под давлением азота. Из-за высокой скорости реакций и большого числа исходных компонентов процесс алюминотермического синтеза ВАС под давлением азота является многопараметрическим и слабоуправляемым, поэтому при выплавке ВАС заданного состава принимались в расчет численные результаты термодинамического моделирования, описанного в работе [8]. Механические свойства полученной стали сравниваются с таковыми для ВАС промышленной выплавки.

\section{2. Материалы и методы исследования}

Чтобы получить аустенит при комнатной температуре химический состав ВАC системы Fe-Cr-Mn-N был выбран исходя из известной фазовой диаграммы Шеффлера -ДеЛонга (Schaeffler-DeLong diagram) для нержавеющих сталей [9]. В качестве реагентов при составлении порошковых смесей использовали следующие материалы: оксиды железа $\mathrm{Fe}_{2} \mathrm{O}_{3}$, хрома $\mathrm{Cr}_{2} \mathrm{O}_{3}$, марганца $\mathrm{MnO}_{2}$, нитрид хрома (смесь состава $80 \% \mathrm{CrN}+20 \% \mathrm{Cr}_{2} \mathrm{~N}$ ) и порошок алюминиевый марки АСД-Ч. Методика и условия плавки представлены в работе [8] и в патенте [10]. Продуктом синтеза являлся металлический слиток состава Fe-23Cr-9Mn-1N массой 0.9 кг со слоем легкоотделяющегося шлака в верхней части. Состав исходной порошковой смеси и полученной ВАС представлены в табл. 1. Насыщение расплава азотом происходило одновременно из газовой фазы и с помощью нитридов хрома в составе шихты. После выплав- ки слитки ковались при $T=1150-1170^{\circ} \mathrm{C}$ до степени деформации $30 \%$, далее разрезались электроискровым методом и закаливались от $1200^{\circ} \mathrm{C}$ с выдержкой 2 часа в воду. Исследования проводили следующими методами: рентгеновская дифракция (ДРОН-6 с монохроматизированным Со $\mathrm{K}_{\alpha}$ излучением), металлография (микроскоп NEOPHOT-21), просвечивающая электронная микроскопия (JEM-100C). Химический анализ на газы и углерод проводили на анализаторе Метавак-АК, а на содержание металлов - на атомно-эмиссионном спектрометре Spectroflame Modula S. Испытания на растяжение проводили на разрывной машине 1958-У10-1.

\section{3. Результаты и обсуждение}

Дифрактограмма стали в литом состоянии (рис. 1a) показывает наличие аустенита (около 50\%) и феррита (около $35 \%$ ). Ясно видно также присутствие нитрида хрома $\mathrm{Cr}_{2} \mathrm{~N}$. Рассчитанный параметр решетки аустенита составляет 0.3597 нм. После ковки происходит увеличение, по сравнению с литой сталью, количества аустенита до $80 \%$ с соответствующим уменьшением количества феррита (до $10 \%$ ) и нитрида хрома (рис. 1b). В результате ковки параметр решетки аустенита возрастает до 0.3624 нм. Отмеченное возрастание параметра решетки аустенита и уменьшение количества нитрида хрома свидетельствуют о растворении нитридов и стабилизации аустенита, представляющего собой твердый раствор азота, хрома и марганца в $\gamma$-Fe.

Табл. 1. Состав исходной шихты и металла после выплавки. Table 1. Composition of initial charge and metal after smelting.

\begin{tabular}{|c|c|c|c|c|c|}
\hline \multicolumn{7}{|c|}{ Шихтовая смесь / Charge mixture } \\
\hline $\mathrm{Fe}_{2} \mathrm{O}_{3}$ & $\mathrm{Cr}_{2} \mathrm{O}_{3}$ & $\mathrm{MnO}_{2}$ & $\mathrm{CrN}$ & $\mathrm{Al}$ \\
\hline 48 & 11 & 12 & 3 & 26 \\
\hline \multicolumn{7}{|c|}{ Металл / Metal } \\
\hline $\mathrm{Cr}$ & $\mathrm{Mn}$ & $\mathrm{N}$ & $\mathrm{C}$ & $\mathrm{O}$ & $\mathrm{Al}$ \\
\hline 23 & 8,6 & 1,15 & 0,07 & 0,03 & 0,08 \\
\hline
\end{tabular}

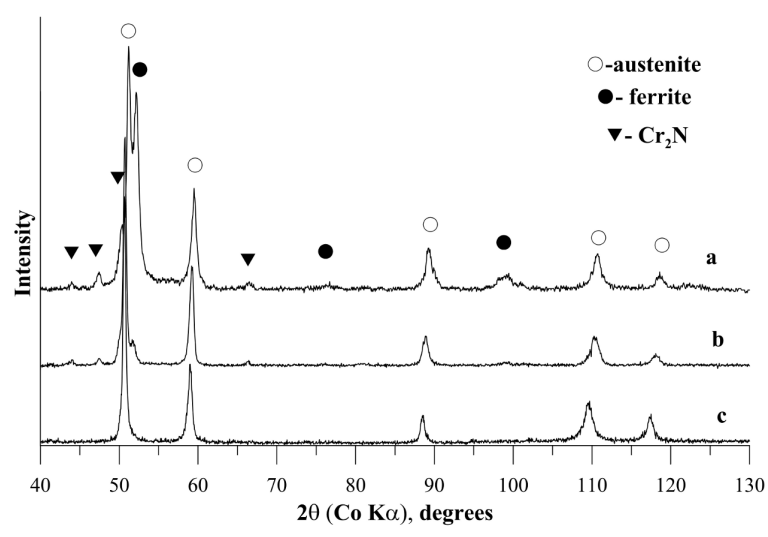

Рис. 1. Рентгеновские дифрактограммы высокоазотистой стали в литом (a), кованом (b) и закаленном (c) состояниях.

Fig. 1. XRD patterns of high-nitrogen steel in as-cast (a), forged (b) and quenched (c) states. 
В микроструктуре стали в литом состоянии при малом увеличении ясно выявляется дендритная структуpa (рис. 2a). При большем увеличении (рис. 2b) видны продукты прерывистого распада пересыщенного азотом аустенита в виде пластин (ламелей) нитридов $\mathrm{Cr}_{2} \mathrm{~N}$, образующих колонии в аустенитной матрице. Такая структуpa BAC напоминает перлит в углеродистой стали, однако $\mathrm{Cr}_{2} \mathrm{~N}$ не является продуктом эвтектоидного превращения, а является результатом прерывистого распада аустенита по реакции $\gamma_{1} \rightarrow \gamma_{2}+\mathrm{Cr}_{2} \mathrm{~N}[11,12]$. Как результат обеднения аустенита по азоту и наличия ликвации легирующих элементов в структуре присутствует $\alpha$-феррит (возможно $\delta$-феррит). Средний размер зерна стали в литом состоянии 16 мкм. Структура стали после горячей ковки похожа на структуру литой стали, только более дисперсная. На рис. 3 представлены микроструктуры прокованного образца, полученные методом просвечивающей электронной микроскопии. Видны (рис. 3а) продукты прерывистого распада - узкие вытянутые частицы $\mathrm{Cr}_{2} \mathrm{~N}$, а на соответствующей дифракционной картине - две системы рефлексов от $\gamma$-матрицы и нитрида $\mathrm{Cr}_{2} \mathrm{~N}$ (ось зоны [110] $\gamma / /[210] \mathrm{Cr}_{2} \mathrm{~N}$ ). В микроструктуре другой области образца на рис. $3 \mathrm{~b}$ кроме частиц $\mathrm{Cr}_{2} \mathrm{~N}$ видны ферритные зерна разной формы и размера (100 - 200 нм). На электроннограмме от данной области присутствуют системы рефлексов от аустенита и феррита (ось зоны [111] $\gamma / /[110] \alpha)$.

После закалки кованого образца, по результатам рентгеновской дифракции, наблюдается единственная фаза - аустенит (рис. 1с). Рассчитанный параметр решетки аустенита закаленной стали составляет 0.3640 нм. При нагреве до $1200^{\circ} \mathrm{C}$ и выдержке в течении 2 ч нитриды хрома растворились в аустените, что привело к увеличению параметра решетки по сравнению с кованым образцом. Аустенит закаленной стали имеет характерную для аустенита нержавеющей стали структуру полиэдральных зерен с двойниками (рис. 2c).

В работе [12] для параметра решетки аустенита CrMnN стали дается выражение (в нм):

$$
\begin{gathered}
a_{\gamma}=0.3578+0.00006 \mathrm{Cr}+0.000095 \mathrm{Mn}+ \\
+0.0033 \mathrm{C}+0.0029 \mathrm{~N},
\end{gathered}
$$

где символы элементов обозначают их содержание в мас.\%. Для химического состава исследуемой стали (табл. 1) получаем 0.3636 нм. Как было показано выше, в течение последовательных обработок: литое состояние, ковка и закалка параметр решетки аустенита $a_{y}$ возрастает в ряду $0.3597,0.3624$ и 0.3640 нм. Возрастание параметра свидетельствует о постепенном насыщении аустенита легирующими элементами за счет растворения в нем, прежде всего нитрида хрома, а также феррита в результате последовательных обработок. Экспериментальное значение параметра аустенита после закалки чуть больше расчетного, что можно объяснить наличием в твердом растворе неучтенных в формуле (1) элементов, таких как кислород и алюминий, присутствующих в составе стали (см. табл. 1). Близость экспериментальных и расчетных значений параметров означает, что все легирующие элементы стали (включая азот) растворены в аустените в результате выдержки при температуре закалки и зафиксированы в твердом растворе закалкой.
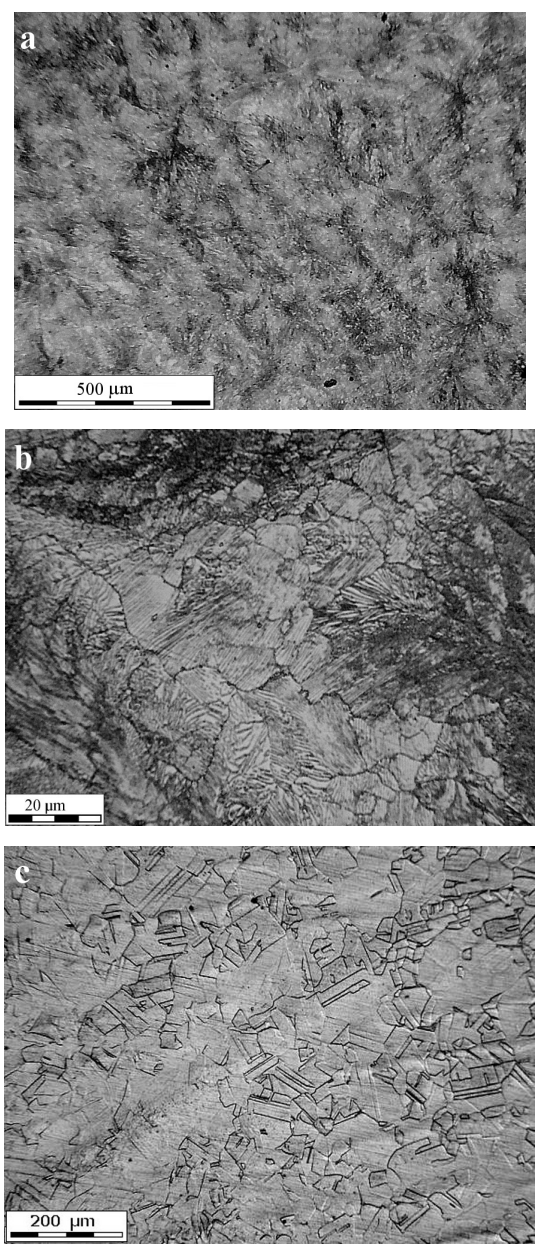

Рис. 2. Микроструктура высокоазотистой стали в литом (a, b) и закаленном (c) состояниях (оптическая микроскопия).

Fig. 2. The microstructure of high-nitrogen steel in as-cast $(a, b)$ and quenched (c) states (optical microscopy).
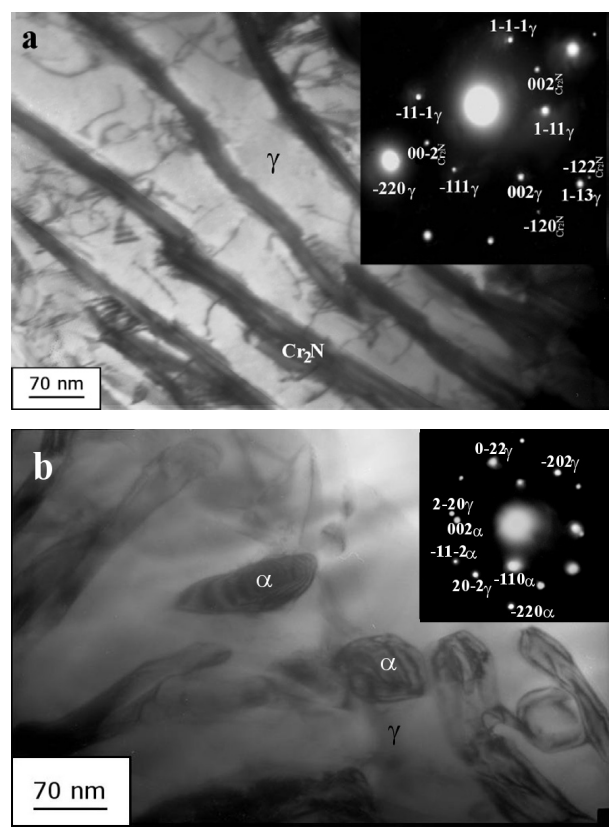

Рис. 3. ПЭМ-изображение микроструктуры и микродифракции кованой стали: (a) [110] $\gamma / /[210] \mathrm{Cr}_{2} \mathrm{~N}$; (b) [111] $\gamma / /[110] \alpha$.

Fig. 3. TEM images of the microstructure and microdiffraction patterns of the forged steel: (a) [110] $\gamma / /[210] \mathrm{Cr}_{2} \mathrm{~N}$; (b) $[111] \gamma / /[110] \alpha$. 
В табл. 2 представлены данные по твердости HRC, а также пределу прочности $\sigma_{\text {в }}$ и относительному удлинению $\delta$ полученной стали в литом (испытание на разрыв не проводили), кованом и закаленном состояниях (испытания проводили при комнатной температуре). Высокие значения твердости литой стали связаны с его мелкозернистой структурой и выделением $\mathrm{Cr}_{2} \mathrm{~N}$ в процессе кристаллизации. При ковке кроме увеличения дисперсности структуры происходит деформационное упрочнение, что объясняет высокие прочностные свойства прокованной стали. В результате дальнейшей термообработки (выдержка 2 ч при $1200^{\circ} \mathrm{C}$ ) происходит полное растворение нитридов хрома, что приводит к существенному повышению пластичности после закалки. В то же время, увеличение количества азота в аустените приводит к дополнительному твердорастворному упрочнению, что объясняет высокие значения твердости и предела прочности для аустенита в закаленной стали.

По данным [13], промышленная высокоазотистая сталь Р900 N (типа 07Х18АГ19) имеет следующие механические свойства при испытаниях на разрыв при комнатной температуре: предел прочности $>900 \mathrm{MПа,} \mathrm{отно-}$ сительное удлинение $48 \%$. Из сравнения механических свойств ВАС, полученных в нашей работе методом алюминотермии и в промышленных условиях методом электрошлакового переплава под давлением азота, можно видеть, что модельная алюминотермическая сталь не уступает по свойствам промышленной стали.

Табл. 2. Механические свойства стали.

Table 2. Mechanical properties of steel.

\begin{tabular}{|c|c|c|c|}
\hline $\begin{array}{c}\text { Состояние стали } \\
\text { State of steel }\end{array}$ & $\begin{array}{c}\text { НRC, ед. } \\
\text { HRC, un. }\end{array}$ & $\begin{array}{c}\sigma_{\mathrm{B}}, \mathrm{MПа} \\
\sigma_{\mathrm{B}}, \mathrm{MPa}\end{array}$ & $\delta, \%$ \\
\hline $\begin{array}{c}\text { Литое } \\
\text { Cast }\end{array}$ & 43 & - & - \\
\hline $\begin{array}{c}\text { Прокованное } \\
\text { Forged }\end{array}$ & 50 & 1230 & 4.9 \\
\hline $\begin{array}{c}\text { Закаленное } \\
\text { Quenched }\end{array}$ & 37 & 1324 & 27 \\
\hline
\end{tabular}

\section{4. Выводы}

Методом алюминотермии под давлением азота получена высокоазотистая сталь состава Fe-23Cr-9Mn-1N (мас.\%). В литом состоянии сталь имеет феррито-аустенитную структуру с пластинчатыми выделениями $\mathrm{Cr}_{2} \mathrm{~N}$ - продуктом прерывистого распада аустенита. Горячая ковка литой стали приводит к измельчению структуры и увеличению доли аустенита в стали. После термообработки кованого образца (закалка в воду от $1200^{\circ} \mathrm{C}$ ) в стали наблюдается единственная фаза высокоазотистый аустенит. Анализ параметра решетки показал, что после закалки все легирующие элементы растворены в аустените образуя ГЦК твердый раствор замещения-внедрения. В результате произошедшей полной аустенизации сталь обладает высокими показателями прочности и пластичности, не уступающими таковым промышленной высокоазотистой стали Р900 N, полученной электрошлаковым переплавом под давлением азота.

\section{Литература/References}

1. J.W. Simmons. Mater. Sci. Engin. A 207 (2), 159-169 (1996). Doi: http://dx.doi.org/10.1016/0921-5093 (95) $09991-3$

2. M. O. Speidel. Metal Sci. Heat Treat. 47 (11), 489-493 (2005). (in Russian) [M. О. Шпайдель. МиТОМ. 11, 9- 14 (2005).] Doi: 10.1007/s11041-006-0017-y.

3. V.V. Berezovskaya, M.V. Kostina, E.V. Blinov, I. O. Bannykh, V.E. Bobrova, V.P. Mel'nik. Russian Metallurgy (Metally). 2008 (1), 29-33 (2008). (in Russian) [В.В. Березовская, М.В. Костина, Е.В. Блинов, И.О. Банных, В.Е. Боброва, В. П. Мельник. Металлы. 2008 (1), 36 - 41 (2008).] Doi: $10.1134 /$ S0036029508010060.

4. V.G. Gavriljuk, H. Berns. High nitrogen steel: structure, properties, manufacture, applications, Springer-Verlag Berlin Heidelberg (1999) 378 p. Doi: 10.1007/978-3-662-03760-7

5. K. Yang, Y.Ren. Sci. Technol. Adv. Mater. 11 (1), 014105-014118 (2010). Doi: 10.1088/1468-996/11/1/ 014105

6. T.V. Rashev. High nitrogen steels. Metallurgy under pressure, Sofia, Bulgarian Academy of Sciences (1995) 268 p. (in Russian) [Ц.В. Рашев. Высокоазотистые стали. Металлургия под давлением, София, БАН, 1995. 268 c.]

7. N.P. Lyakishev, Yu. L. Pliner, G. F. Ignatenko, S. I. Lappo. Aluminothermy, Metallurgiya, Moscow (1988) 424 p. (in Russian) [Н.П. Лякишев, Ю.Л. Плинер, Г.Ф. Игнатенко, С.И. Лаппо. Алюминотермия, М.: Металлургия (1988) 424 c.]

8. G. A. Dorofeev, V.A. Karev, E.V. Kuzminykh, V.I. Lad'yanov, A.N. Lubnin, A.S. Vaulin, M. I. Mokrushina. Russian Metallurgy (Metally). 2013 (1), 1 - 10 (2013). (in Russian) [Г. А. Дорофеев, В.А. Карев, Е.В. Кузьминых, В.И. Ладьянов, А.Н. Лубнин, А.С. Ваулин М.И. Мокрушина. Металлы. 2013 (1), 3- 14 (2013).] Doi: 10.1134/S0036029513010047.

9. G. Balachandran, M. L. Bhatia, N. B. Ballal, P. Krishna Rao. ISIJ Intern. 41 (9), 1018 - 1027 (2001). Doi: http://doi.org /10.2355/isijinternational.41.1018

10. Patent RF № 2446215, 27.03.2012. (in Russian) [Патент PФ №2446215, 27.03.2012].

11. P.A. Carvalho, I.F. Machado, G. Solorzano, A. F. Padilha. Phil. Magaz. 88 (2), 229-242 (2008). Doi: $10.1080 / 14786430701805590$

12. N.C. S. Srinivas, V.V. Kutumbarao. Scr. Mater. 37 (3), 285 - 291 (1997). Doi: http://dx.doi.org/10.1016/S13596462 (97) $00112-7$

13. http://www.energietechnik-essen.de/de/produkte/ stickstoffstaehle/druckaufgestickte-austenite.html. 